\title{
The Vexing Problem of Ventilator-Associated Pneumonia: Observations on Pathophysiology, Public Policy, and Clinical Science
}

\author{
Richard H Kallet MSc RRT FAARC
}

\author{
Introduction \\ Inherent Limitations in Diagnosing Ventilator-Associated Pneumonia \\ Socioeconomic Context of Ventilator-Associated Pneumonia Reporting \\ Ventilator-Associated Events as a Potential Solution \\ Initial Studies on Ventilator-Associated Event Surveillance \\ Pathophysiology of Ventilator-Associated Pneumonia: Microaspiration and \\ Endotracheal Tube Design \\ Modifiable Risk Factors for Ventilator-Associated Pneumonia \\ Endotracheal Tube Design and Monitoring \\ Noninvasive Ventilation \\ Weaning and Sedation Strategies \\ Semirecumbent Positioning \\ Non-Modifiable Risk Factors for Ventilator-Associated Pneumonia \\ Impact of Poverty and Homelessness \\ Traumatic Injuries \\ Do Zero Ventilator-Associated Pneumonia Rates With Bundled Care \\ Possess Evidence-Based Credibility? \\ Summary
}

\begin{abstract}
Ventilator-associated pneumonia (VAP) is an acquired infection related primarily to the consequences of prolonged endotracheal intubation. It is considered the most important infectious challenge in the critical care setting. Preventable complications of hospital care are considered an important source of wasted health-care costs believed to consume up to $47 \%$ of annual expenditures in the United States. Whether VAP is preventable has become a highly contentious debate since public reporting commenced a decade ago. This selective review focuses on specific aspects of this debate, including the inherent vagaries in the diagnosis of VAP and the marked disparities between VAP rates based on clinical diagnosis versus surveillance data. Also discussed is how this debate has impacted public policy, leading to the new paradigm of ventilator-associated events. The limited ability of artificial airways to prevent microaspiration and biofilm build-up, as well as non-modifiable conditions increasing the risk of VAP, is described in detail. In addition, the origins of the mistaken but widely embraced notion that zero VAP is a realistic achievement are examined. Key words: artificial airway; endotracheal tube; microaspiration; ventilator-associated pneumonia; ventilator-associated events. [Respir Care 2015;60(10):1495-1508. () 2015 Daedalus Enterprises]
\end{abstract}

\section{Introduction}

Ventilator-associated pneumonia (VAP) is an acquired infection not present (or incubating) at the initiation of mechanical ventilation; therefore, it is defined as pneumonia that occurs $>48 \mathrm{~h}$ after intubation. ${ }^{1}$ Insertion of an endotracheal tube (ETT) inadvertently colonizes the lower respiratory tract, ${ }^{2}$ and its presence inhibits natural defense mechanisms that prevent infection. The ETT reduces tracheobronchial mucus flow by half, resulting in retained secretions and the development of pneumonia., ${ }^{3,4}$ VAP is caused primarily by microaspiration of infected oropha- 
ryngeal secretions pooled above the ETT cuff and represents the most important infectious challenge in the critical care setting. ${ }^{5}$ Both the incidence of VAP and attributable mortality are difficult to discern, but are estimated to occur in $9-28 \%$ of mechanically ventilated patients, ${ }^{6}$ with an attributable mortality of 3-17\%.7 VAP has been estimated to prolong the duration of mechanical ventilation by up to $11 \mathrm{~d}$, increase hospitalization stay by $6-25 \mathrm{~d}$, and incur additional expenditures ranging from $\$ 12,000$ to $\$ 40,000$ per episode. ${ }^{1,8-14}$

Annual health-care costs in the United States are approximately $\$ 2-2.7$ trillion (17\% of the gross domestic product), but these expenditures do not improve patient outcomes relative to other advanced nations that spend substantially less on health care. ${ }^{15,16}$ Between 21 and $47 \%$ of these expenditures are believed to be consumed by waste, ${ }^{15}$ with preventable complications being an obvious source. Within this context, $<1 \%$ of total health-care expenditures in the United States are devoted to technology assessment geared toward evaluating interventions that improve value to both consumers and payers. ${ }^{16}$ To deal with this, the United States has been moving inexorably toward applying the principles of value engineering and value analysis (originally developed by manufacturers in the 1940s) to the health-care industry. ${ }^{16}$ This has been a catalyst for health-care reform and a shift from a volumebased payment (ie, fee-for-service) to a pay-for-performance scheme. A prominent focus in value analysis is interventions aimed at reducing medical complications.

A major effort to reduce preventable morbidity and mortality in health-care delivery has been spearheaded in part by the Institute for Healthcare Improvement. One of its areas of focus has been preventing VAP through the implementation of bundled care.${ }^{17}$ However, these initiatives have engendered considerable controversy, in particular, how evidence concerning the nature of VAP and its response to prevention strategies has been interpreted and, in turn, has influenced recent health-care policy proposals.

This review focuses on specific areas concerning VAP. These include the limitations of diagnosing VAP and how this informs the tension between clinical and administrative data, as well as explaining why the new paradigm of ventilator-associated events (VAE) was necessary. Central to this

Mr Kallet is affiliated with Respiratory Care Services, Department of Anesthesia, University of California, San Francisco at San Francisco General Hospital, San Francisco, California.

Mr Kallet has disclosed no conflicts of interest.

Correspondence: Richard H Kallet MSc RRT FAARC, Department of Anesthesia, UCSF at SFGH, NH:GA-2, 1001 Potrero Avenue, San Francisco, CA 94110. E-mail: rich.kallet@ucsf.edu.

DOI: $10.4187 /$ respcare. 03774 discussion is how recent trends in health-care benchmarking and proposed reimbursement strategies may negatively impact hospitals, particularly those institutions providing care primarily to high-risk populations (eg, major urban public hospitals, academic referral hospitals, and trauma centers). In recent years, a misguided expectation has emerged among health-care administrators and public policy officials alike that VAP rates can be brought to zero. Properly evaluating the feasibility of this expectation requires discussing the key determinants of VAP: the limitations imposed by the artificial airway, as well as the impact of both modifiable and nonmodifiable risk factors. Finally, some observations will be offered on the dubious and uniquely American notion of eradicating (zapping) VAP.

\section{Inherent Limitations in Diagnosing Ventilator-Associated Pneumonia} One cannot discuss what VAP means for our pa-
tients and hospitals until one determines how to
diagnose and track it-Shorr et $\mathrm{al}^{11}$

Simply labeling an event 'VAP' does not make it so-Magill et al ${ }^{18}$

The clinical diagnosis of VAP is highly inaccurate, as $\sim 50 \%$ of cases show no evidence of pneumonia at autopsy. ${ }^{19}$ Likewise, in some studies, up to $60 \%$ of clinically diagnosed VAP could not be confirmed by microbiological cultures. ${ }^{1,20}$ Substantial over-diagnosis (58\%) of VAP has also been reported when clinically diagnosed cases are subsequently adjudicated by expert, multidisciplinary committees. ${ }^{21}$ This is because clinical criteria used to diagnose VAP are partly based upon non-specific signs common to other conditions (eg, ARDS, sepsis, trauma), whereas other signs are inherently subjective (eg, changes in sputum characteristics and chest radiographs, deteriorating oxygenation). Even when these clinical signs are conjoined with microbiological data, the estimated VAP rate varies widely. ${ }^{22}$ The problem of diagnosing VAP is complicated further because positive microbiological findings from sputum cultures are not definitive for diagnosing pneumonia. ${ }^{22}$ In some reports, negative sputum cultures missed between 15 and $56 \%$ of pneumonias discovered at autopsy..$^{23,24}$

Moreover, VAP can be confused with ventilator-associated tracheobronchitis, which is a nosocomial infection of the tracheobronchial tree, but not the lung tissue itself. ${ }^{10}$ Ventilator-associated tracheobronchitis has the same clinical and microbiological signs as VAP, but without deteriorating oxygenation and chest radiographic findings. However, it can be misdiagnosed as VAP when it coincides with other pulmonary conditions such as atelectasis or pulmonary edema. Between 10 and $30 \%$ of ventilator- 


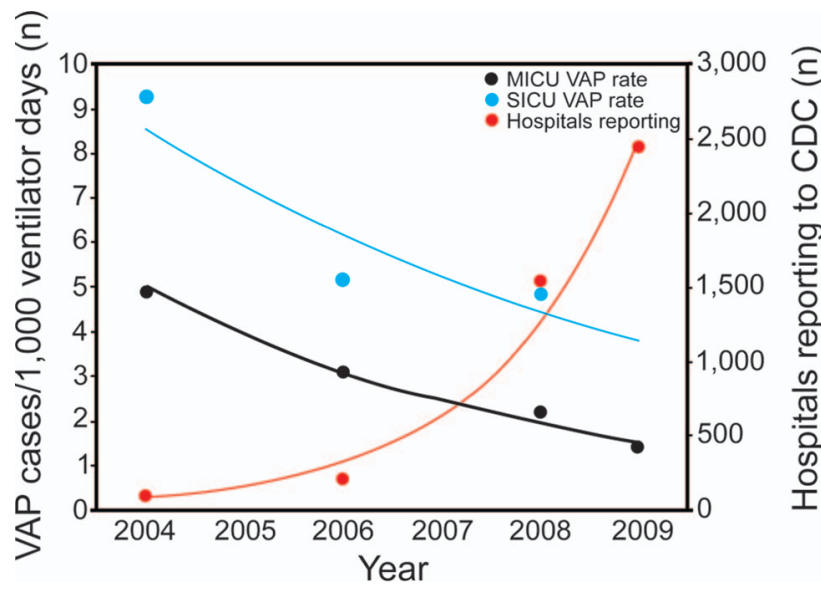

Fig. 1. Relationship between ventilator-associated pneumonia (VAP) cases and public reporting of VAP to the Centers for Disease Control and Prevention (CDC). MICU = medical ICU. SICU = surgical ICU.

Historically, hospital-acquired infections were not considered preventable, and their consequences were limited to intra-institutional monitoring. ${ }^{34}$ Now that hospital-acquired infections are publically reported through the NHSN, 2,32 VAP is considered to be a relative medical error with predictable consequences. ${ }^{11}$ Recently, the Centers for Medicare and Medicaid Services (CMS) considered designating VAP as a non-reimbursable event, whereas The Joint Commission considered incorporating VAP into both the rating and accreditation of hospitals. ${ }^{26,28,33,34}$ This would have a profoundly negative impact on the reputation of hospitals with significant economic consequences.

Since public reporting of VAP surveillance rates to the CDC/NHSN began a decade ago, there has been a steady and marked decrease in the incidence of VAP (Fig. 1). Curiously, this has occurred without a corresponding reduction in antibiotic usage. ${ }^{27}$ More than $50 \%$ of non-academic medical ICUs are now reporting VAP rates of zero. ${ }^{35}$ The response to these trends in the medical literature has been one of pervasive skepticism. ${ }^{26,27,33,36-51}$ In fact, VAP experts have pointedly criticized the growing misperception that administrative surveillance methods reflect the true incidence of ventilatorassociated tracheobronchitis/VAP. ${ }^{29}$ This skepticism is buttressed by observations that validation studies examining surveillance techniques have found that infection-control surveyors miss almost one third of VAP cases. ${ }^{27}$

There is speculation that increased pressure from public-reporting requirements in the United States has, at best, induced a bias toward very conservative interpretation of subjective elements used in surveillance criteria ${ }^{11,36,37,46}$ and, at worst, has raised suspicion that some institutions are gaming the system. ${ }^{18,48} \mathrm{~A}$ recent study by the International Nosocomial Infection Control Consortium (INICC) that used the CDC/NHSN diagnostic criteria (and employed intensive preventive measures) reported a $22 \%$ relative reduction in VAP; nonetheless, VAP rates remained 5 times

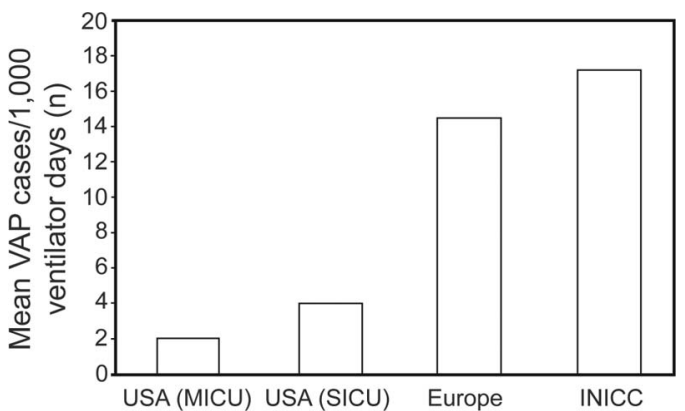

Fig. 2. Comparison of ventilator-associated pneumonia (VAP) rates publically reported in the United States with those in European and other comparable nations. Data from Reference 37. MICU = medical ICUs. SICU = surgical ICUs. INICC = International Nosocomial Infection Control Consortium.

higher than in the United States. ${ }^{45}$ Interestingly, the INICC post-intervention rates are similar to those reported in Europe, where, until approximately 2012, public reporting of VAP was not required in many countries (Fig. 2). ${ }^{44}$ Given the simplicity of VAP prevention measures, the stark contrast in VAP incidence between the United States and the rest of the world invites skepticism.

\section{Ventilator-Associated Events as a Potential Solution}

The truth is that it might be possible to achieve an apparent VAP rate of zero by maximally exploiting the subjectivity and inconsistencies of VAP definitions-Klompas et al ${ }^{50}$

Benchmarking health-care performance on the basis of best practices has reasonable validity for unambiguous problems (eg, pressure ulcers, falls). However, the situation is qualitatively different with VAP, wherein "the key to benchmarking has to be a defined, unequivocal diagnosis." ${ }^{33}$ Yet the diagnostic accuracy of VAP is poor, and irrespective of preventive measures, the incidence is highly dependent upon non-modifiable patient risk factors. ${ }^{1}$ Thus, VAP is widely viewed as an unreliable measure of a hospital's quality of care. ${ }^{28,33,39,43}$ In particular, public hospitals providing care to patients at high risk for VAP (eg, trauma, neurologically injured, immunocompromised, poor health associated with poverty, alcoholism) are likely to be penalized. ${ }^{39}$

Because of these concerns, the National Quality Forum (used by the CMS for selecting health-care quality-reporting measures) requested that the $\mathrm{CDC}$ propose a new VAP surveillance scheme. ${ }^{34}$ In fact, the CMS decided not to include VAP in its in-patient quality reporting because of protests from the health-care professions. ${ }^{51}$ After several failed attempts by the CMS to develop a satisfactory new surveillance method on their own, the Department of Health and Human Services then approached the CDC and the 
Critical Care Societies Collaborative. ${ }^{51}$ Both groups, along with representatives from the IDSA, convened a Surveillance Definition Working Group in 2011 to develop a more credible VAP definition for use by the NHSN. ${ }^{18}$

After further testing and iterations are completed, the new NHSN surveillance criteria might be used for public reporting and perhaps pay-for-performance. ${ }^{34}$ The new surveillance concept and definition of VAE were published in 2012. The focus has been shifted away from VAP and broadened toward generalized complications of critical illness manifested as deteriorating lung function in mechanically ventilated patients. The intention of VAE is to make surveillance as objective as possible so as to facilitate automation, improve comparability between institutions, and ostensibly lessen the ability to game the system. ${ }^{35}$ More importantly, when coupled with measures of severity-of-illness scores, these new definitions might allow for credible risk adjustments when hospitals are benchmarked against one another. ${ }^{35}$

In the new VAE model, before considering VAP as a diagnosis, certain precursor clinical events must be fulfilled. These include specific objective criteria related to deterioration in lung function (ventilator-associated condition [VAC]) and its coincidence with both laboratory values and institution of (or changes in) antibiotic administration (infection-related, ventilator-associated complication [IVAC]). ${ }^{18}$ Both VAC and IVAC constitute a VAE and are intended for public-reporting purposes. ${ }^{18}$ Once these conditions have been met, varying levels of microbiological evidence that appear within $2 \mathrm{~d}$ prior to or following deterioration in pulmonary function are used to make a diagnosis of either possible or probable VAP (Fig. 3). Both possible and probable VAP will likely be limited to intra-institutional quality-improvement measurements.

\section{Initial Studies on Ventilator-Associated Event Surveillance}

So with VAE surveillance, we do not know what we are detecting or what to do about it, but we can detect it faster and easier-Wunderink et $\mathrm{al}^{48}$

Several studies have assessed the likely impact of VAE on public reporting. A retrospective 6-y study of 20,000 subjects at a large urban hospital and level I trauma center reported the prevalence of VAC of between 5 and $10 \%$ with a corresponding incidence density of between 10 and 16 cases/1,000 ventilator days for medical, surgical, and neurologically injured subjects. ${ }^{48}$ The corresponding IVAC rate was $\sim 2-4 \%$ with an incidence density of 4-7 cases/1,000 ventilator days. In a prospective surveillance study of 2,300 subjects at 2 Dutch hospitals, the prevalence of VAC was 7\% with an incidence density of

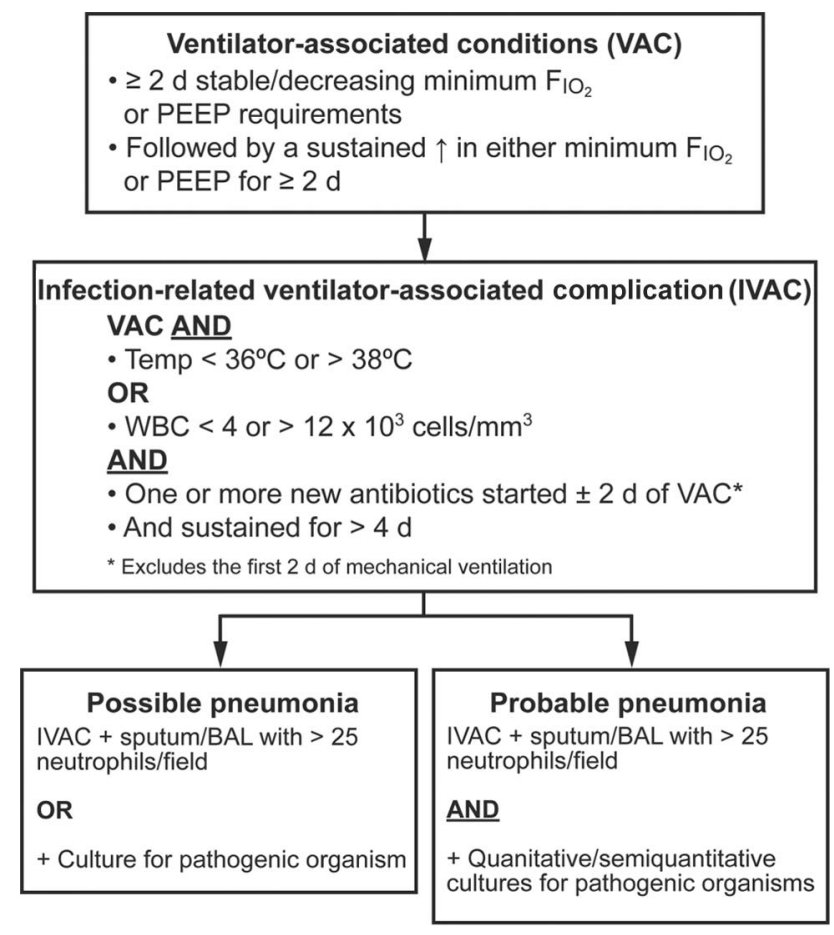

Fig. 3. Flow diagram for determining a ventilator-associated event. $\mathrm{WBC}=$ white blood cells. $\mathrm{BAL}=$ bronchoalveolar lavage.

10 cases/1,000 ventilator days, and that of IVAC was $3 \%$ with 4.2 cases/1,000 ventilator days. ${ }^{52}$ Similar findings were also reported in a 7-y retrospective study of the Mayo Clinic's medical ICUs with VAC and IVAC rates of $11 \%$ and $4 \%$, respectively, ${ }^{46}$ and in a retrospective multi-center study of 1,320 subjects with VAC and IVAC prevalence of $\sim 11 \%$ and $5 \%$, respectively. ${ }^{53}$ Most importantly, VAE captured a distinct subset of subjects who had higher morbidity and mortality..$^{53,54}$

There is a concern over of the wisdom of unlinking VAP surveillance from clinical management of patients with suspected VAP, particularly as improved antibiotic stewardship has been projected as a potential benefit of the new classification schema. ${ }^{48}$ The concordance between VAE and VAP appears dubious. Klein Klouwenberg et al ${ }^{52}$ reported that the VAE algorithm captured, at best, only $32 \%$ of prospectively identified cases of VAP. Chang et al ${ }^{55}$ found a progressively weakened associated between VAE criteria and VAP wherein VAC and IVAC captured 33\% and $24 \%$ of VAP identified by an expert review committee, respectively, whereas the agreement with possible and probably VAP designations was only $12 \%$ and $1 \%$. Likewise, Stoeppel et al ${ }^{56}$ reported that VAE definitions failed to identify a substantial number of surgical subjects with VAP because these subjects never had a period of stable/decreasing oxygenation requirements. These findings are supported by other evidence that VAE underestimate the incidence of pneumonia, ${ }^{46,53}$ thus reinforcing the long- 
standing controversy that surveillance data systematically underestimate the clinical incidence of VAP.

As the evidence presented above suggests, the interpretation and suitability of VAE for benchmarking hospital quality of care have yet to be established. Moreover, because VAE reflect a broad range of clinical conditions, it is currently unknown if any of the underlying causes leading to VAE can be affected by preventive measures. ${ }^{52}$ For instance, a high incidence of VAE occurs on mechanical ventilation days 3-4, which suggests that early VAE likely represent the progression of underlying disease processes and not necessarily a reflection of inadequate care. ${ }^{52,57,58}$ As an example, the pathologic evolution of pulmonary contusion (itself a risk factor for pneumonia) typically reaches peak pulmonary decompensation at $\sim 72 \mathrm{~h}$ postinjury. ${ }^{59}$ Another issue is that the results of VAE monitoring will differ depending on whether data are collected electronically or manually and particularly on the intensity of electronic data capture. ${ }^{52}$

More importantly, retrospective studies suggest that VAP prevention bundles do not affect the incidence of VAE. ${ }^{46,53,57}$ This is not unexpected, as VAE capture both infectious and non-infectious causes of respiratory deterioration, as well as infectious complications not emanating from the lungs. These findings coincide with the National Quality Forum's decision to unendorse the Institute for Healthcare Improvement's ventilator bundle in $2013 .{ }^{49}$

\section{Pathophysiology of Ventilator-Associated Pneumonia: Microaspiration and Endotracheal Tube Design}

VAP is directly related to the duration of mechanical ventilation; the risk is $\sim 3 \% / \mathrm{d}$ during the first $5 \mathrm{~d}, 2 \%$ on days $6-10$, and $1 \% / d$ thereafter. ${ }^{1,60}$ Late-onset VAP (occurring on or after $5 \mathrm{~d}$ of mechanical ventilation) is caused primarily by pathogenic Gram-negative bacteria associated with greater morbidity and mortality. ${ }^{61}$ It accounts for $62-73 \%$ of all cases, with the highest daily hazard rates of $2-4 \%$ reported to occur between days 6 and 8. ${ }^{61-63}$

Whether VAP can be eradicated requires discussion of both VAP pathophysiology and ETT design limitations. To begin with, terms such as VAP and VAE are unfortunate misnomers. In the early 1960s, when modern mechanical ventilation was in its infancy, the ventilator circuit (which often included nebulizers for humidification) was directly implicated in causing nosocomial pneumonia and was referred to as a respirator lung. ${ }^{64}$ For decades afterwards, the standard practice was to change ventilator circuits on at least a daily basis. Over the past 30 years, there has been extensive research into the role of the ventilator circuit as a source of VAP. In essence, the ventilator circuit plays a minor role in VAP, as: (1) it is the patient (and the ETT) who invariably colonizes the circuit, and (2) drastically reducing the frequency of circuit changes has had no impact on the frequency of VAP. ${ }^{65,66}$ Rather, clinician behavior in manipulating the circuit (eg, hand hygiene when breaking the circuit, care in handling resuscitator bags or circuit during disconnections) is the most likely source of patient inoculation. ${ }^{66}$

The predominant source of VAP is chronic microaspiration of oropharyngeal secretions pooled above the ETT cuff that occurs in as many as $88-100 \%$ of intubated patients. ${ }^{67,68}$ These secretions accumulate in the subglottic space and therefore cannot be effectively removed by suctioning the oral cavity. The volume capacity of this space is $\sim 10 \mathrm{~mL}$, and the accumulation of large secretion volumes $(100-150 \mathrm{~mL} / \mathrm{d})$ has been reported. ${ }^{69}$ ETT cuffs are typically made of polyvinyl chloride, which has limited distensibility and therefore requires the cuff to be of a diameter that, when appropriately inflated, is $50 \%$ greater than the trachea (which is $\sim 20 \mathrm{~mm}$ ). ${ }^{70,71}$ As a result, the excess cuff volume forms longitudinal folds (microchannels) into which, depending upon secretion viscosity, infected oropharyngeal or gastric secretions chronically seep and inoculate the lungs, even under conditions of clinically excessive cuff-inflation pressures $\left(50 \mathrm{~cm} \mathrm{H}_{2} \mathrm{O}\right) .32,68,72$

The human trachea is a dynamic, distensible organ of varying size, shape, and tone altered by drugs, posture, head position, and the mere act of ventilation..$^{73}$ It is essentially impossible, despite obtaining a good cuff seal, to fully prevent microaspiration. Moreover, unavoidable ETT movement that occurs during routine care (and particularly during intra-hospital transport) enhances microaspiration. $^{72,74,75}$ This is supported by evidence suggesting that unavoidable movement of the ETT related to routine care such as ETT repositioning is an independent risk factor for VAP (odds ratio of $3.11,95 \%$ CI $1.03-9.42, P=.04$ )..$^{76}$

Attaining a cuff seal that prevents gross aspiration around the ETT requires intra-cuff pressures of $20-30 \mathrm{~cm} \mathrm{H}_{2} \mathrm{O}$. When cuff pressure falls to $15 \mathrm{~cm} \mathrm{H}_{2} \mathrm{O}$, rapid fluid leakage into the lungs may occur. ${ }^{74}$ Microaspiration also happens during loss of PEEP during circuit disconnections and when negative intrathoracic pressures develop during routine suctioning. ${ }^{74,77,78}$ In addition, ETT cuffs slowly lose their volume from the effects of continuous positive intrathoracic pressure and the imperfect, mass-produced, one-way valves separating the pilot balloon from atmospheric pressure. ETT cuffs require replenishing, often several times a day, to maintain an adequate seal, thus signifying that some degree of microaspiration is essentially unavoidable.

ETTs are made of polyvinylchloride plastics, to which most bacteria readily adhere, and become partially or completely coated. ${ }^{79}$ Within days of endotracheal intubation, the internal lumen of the tube is coated with biological material (eg, mucoproteins, fibrin, blood cells) that pathogenic bacteria and molds adhere to and that provides an excellent medium for growth, as well as the potential for enhanced virulence from comingling with other patho- 
gens. ${ }^{80,81}$ Moreover, in mechanically ventilated patients receiving antibiotic therapy for pulmonary infections, bacteria growing within the biofilm are protected from antibiotics. In consequence, there is the potential for repeated re-inoculation of the lower respiratory tract as bacterial aggregates break off with routine suctioning or from sheer forces during inspiratory gas flow. ${ }^{80}$

Small observational studies suggest that biofilm formation on ETTs may be a significant risk factor for VAP. In one study, $80 \%$ of subjects with VAP were found to have advanced (stage IV) biofilm within the ETT lumen. ${ }^{82}$ In another study, the presence of contaminated biofilm in subjects intubated for at least $8 \mathrm{~d}$ resulted in a 7-fold increase in VAP risk. ${ }^{81}$ In a small prospective study on subjects intubated for an average of $6 \mathrm{~d}$, daily use of the Mucus Shaver device to clean the internal lumen of the ETT markedly reduced bacterial colonization compared with controls $(8 \%$ vs $83 \%$ colonization, $P<.001) .{ }^{83} \mathrm{Al}-$ though not significant, the VAP rate was also lower $(8 \%$ vs $25 \%$ ).

\section{Modifiable Risk Factors for Ventilator-Associated Pneumonia}

\section{Endotracheal Tube Design and Monitoring}

Specialized ETTs allow suctioning of the subglottic space above the cuff, and a recent meta-analysis reported a 50\% reduction in VAP risk using subglottic drainage tubes. ${ }^{32}$ Some newer tube designs have also incorporated an ultrathin $(7 \mu \mathrm{m})$ polyurethane cuff that greatly reduces fluid leakage in vitro. ${ }^{67}$ Combining subglottic drainage tubes with the polyurethane cuff design decreased VAP by $64 \% .72$ A recent meta-analysis of 13 randomized clinical trials estimated a risk reduction of $45 \%$ and delayed onset of VAP by an average of $2.7 \mathrm{~d}$ in those managed with subglottic drainage tubes. ${ }^{84}$

Laboratory studies have consistently demonstrated that polyurethane-cuffed ETTs (and similarly designed silicone cuffs) are superior to standard polyvinyl cuffs in minimizing fluid leakage. ${ }^{70,71,75,85-87}$ Significantly reduced microaspiration has been reproduced in clinical trials, ${ }^{75,78}$ coinciding with significant reductions in VAP $(26-45 \%$ relative decrease) ${ }^{88-90}$ However, others have not been able to demonstrate the superiority of polyurethane-cuffed ETTs in reducing microaspiration. ${ }^{91}$ Use of specialized ETTs may be of particular benefit in trauma and acute brain injury patients. These patients often require frequent intra-hospital transportation, which, in itself, is independently associated with a 3-5-fold increased risk for VAP. ${ }^{92,93}$ Thus, despite the best designed ETTs to date, VAP can be reduced substantially, but not eliminated.

Under-inflation $\left(<20 \mathrm{~cm} \mathrm{H}_{2} \mathrm{O}\right)$ of ETT cuff pressure is an independent risk factor for VAP. ${ }^{94}$ Continuous moni- toring and control of tracheal cuff pressures have been shown to maintain adequate ETT cuff pressure and reduce the incidence of both microaspiration and VAP. ${ }^{95,96}$ In these studies, automatic control of ETT cuff pressure maintained between 20 and $30 \mathrm{~cm} \mathrm{H}_{2} \mathrm{O}$ in $98-100 \%$ of observations reduced the incidence of VAP by $51-62 \%$. Among controls, the percentage of subjects with incidences of ETT cuff pressure of $<20 \mathrm{~cm} \mathrm{H}_{2} \mathrm{O}$ ranged from 9 to $55 \%$. Although maintaining adequate ETT cuff pressure is important in reducing microaspiration, it cannot eliminate the risk, as other unavoidable factors such endotracheal suctioning and patient movement contribute to the problem. ${ }^{95}$

\section{Noninvasive Ventilation}

By obviating the need for endotracheal intubation, noninvasive ventilation (NIV) should diminish the incidence of VAP. Numerous studies of NIV have reported the incidence of VAP, usually as a secondary outcome. A metaanalysis of these studies found that NIV substantially decreased the risk of VAP compared with invasive mechanical ventilation (odds ratio of $0.15,95 \%$ CI $0.04-0.58$, $P=.006) .{ }^{97}$ An extensive 3 -y surveillance study involving $\sim 790,000$ critically ill subjects compared VAP rates of those managed with invasive mechanical ventilation or NIV and those not requiring mechanical support. ${ }^{98}$ Of the 6,869 cases of nosocomial pneumonia, $85 \%$ occurred in those requiring invasive mechanical ventilation compared with $2 \%$ associated with NIV and $13 \%$ in those not requiring mechanical assistance. Unfortunately, NIV is appropriate in a circumscribed patient population with acute respiratory failure (eg, COPD exacerbation, cardiogenic pulmonary edema), which limits its utilization as a strategy for reducing VAP.

\section{Weaning and Sedation Strategies}

As discussed above, VAP is directly related to the duration of mechanical ventilation. Late-onset VAP accounts for both the majority of cases and the greatest associated morbidity and mortality, ${ }^{61}$ with the highest risk occurring between days 6 and 8 of mechanical ventilation. ${ }^{61-63}$ In the early 1990s, the average duration of mechanical ventilation was 7-12 d, with an additional average of 3-5 d for weaning using various techniques driven by protocols. ${ }^{99} \mathrm{In}$ a contemporaneous survey of clinicians, the average duration of weaning ranged from 5 to $18 \mathrm{~d}$, with the longest duration associated with synchronized intermittent mandatory ventilation combined with pressure support ventilation. ${ }^{100}$ However, more contemporary studies have reported that the average duration of mechanical ventilation now is $\sim 5-7$ d. ${ }^{45,46,101-103}$ This invites speculation that the incidence of VAP likely was much greater before modern weaning and sedation practices. 
Daily sedation interruptions or spontaneous breathing trials are core aspects of the VAP bundle and have been demonstrated to significantly reduce the average duration of mechanical ventilation by $1.5-3 \mathrm{~d} \cdot .^{99,101,103,104}$ If one assumes a 2-d incubation period from inoculation to VAP onset, then lowering the average duration of mechanical ventilation from 6 or 7 to $\sim 4 \mathrm{~d}$ might further reduce the incidence of VAP, yet the direct impact of daily sedation interruption and spontaneous breathing trial strategies on the incidence of VAP has not been rigorously studied. Observational studies from both medical and surgical ICUs have reported that spontaneous breathing trials and targeted/daily sedation interruptions (irrespective of other VAP prevention measures) reduced the prevalence of VAP from $\sim 15$ to $5 \%$. This corresponded with a decrease in the mean duration of mechanical ventilation to fewer than $5 \mathrm{~d} .{ }^{105,106}$ In another study, targeted sedation reduced the average duration of mechanical ventilation from 10.3 to $4.4 \mathrm{~d}$ with a corresponding trend toward reduced VAP from 20.4 to $8.3 \%(P=.10) .{ }^{107}$

\section{Semirecumbent Positioning}

Perhaps no other aspect of the VAP bundle is as emblematic of the evidence-based limitations of VAP prevention as patient positioning. Supine mechanically ventilated subjects with nasogastric tubes had a substantially higher incidence of aspirating orogastric secretions and microbial colonization compared with subjects managed in the semirecumbent position with head-of-bed elevated to $45^{\circ} .{ }^{108}$ Nonetheless, there continued to be a substantial incidence $(32 \%)$ of lower airway colonization when subjects were positioned at $45^{\circ}$. Others have reported no difference in the incidence of gastroesophageal reflux (54\%) into the oropharynx in mechanically ventilated subjects with nasogastric tubes who are placed in a supine versus semirecumbent position with head-of-bed elevated to 30 $45^{\circ} .109$

Drakulovic et al ${ }^{110}$ reported a significantly higher incidence of confirmed VAP (23\% vs $5 \%, P=.02)$ when comparing supine to semirecumbent position at $45^{\circ}$. Moreover, there was significant interaction between enteral feeding and supine positioning and the incidence of VAP. The authors emphasized the importance of nasogastric tubes in facilitating gastroesophageal reflux by compromising lower esophageal sphincter function. Although smaller nasogastric tubes are thought to interfere less, it appears that nasogastric tubes with inner diameters of 3-6 $\mathrm{mm}$ neither prevented nor reduced gastroesophageal reflux or microaspiration in mechanically ventilated subjects in the semirecumbent position. ${ }^{111}$

Unfortunately, the feasibility of maintaining critically ill subjects semirecumbent at a head-of-bed elevation of $45^{\circ}$ was been found to be unachievable in a multi-center ran- domized trial despite extraordinary oversight by researchers. ${ }^{112}$ Subjects in the intervention arm could be maintained only at $24-32^{\circ}$ elevation, and compared with the control arm (supine with head-of-bed elevated to $10-15^{\circ}$ ), the incidence of confirmed VAP was not different (10.7\% vs $6.5 \%$ ). Interestingly, there was no difference in the actual head-of-bed elevation within each treatment arm that could distinguish those who developed VAP from those who did not.

A previous systematic review ${ }^{113}$ and meta-analysis ${ }^{114}$ of 3 clinical trials of subject positioning and VAP came to opposite conclusions. The former found the evidence inconclusive whether semirecumbent positioning at $45^{\circ}$ headof-bed elevation is either effective or harmful, whereas the latter stressed that positioning subjects at $15-30^{\circ}$ head-ofbed elevation was ineffective, but positioning at $45^{\circ}$ reduced clinically diagnosed VAP. The conclusions of the meta-analysis were strongly criticized, however, based upon the degree of heterogeneity between studies. ${ }^{115}$ The authors of the meta-analysis conceded their own concern regarding the heterogeneity and the limited number of studies from which to draw conclusions. ${ }^{116}$

\section{Non-Modifiable Risk Factors for Ventilator-Associated Pneumonia}

\section{Impact of Poverty and Homelessness}

Public hospitals in particular treat a significant number of patients who live in poverty, many of whom are homeless. Lack of oral health leading to periodontitis and decayed teeth is prominent among this population, with a 11.6-17.5-fold greater risk for oral disease. ${ }^{117-119}$ This population is commonly colonized with pulmonary pathogens and has higher incidences of both community-acquired and health care-associated pneumonia. ${ }^{120}$ In a study of the homeless in Los Angeles, 58\% had severe, untreated dental caries. ${ }^{118}$ Sixty-five percent of ICU subjects had dental plaque/oral mucosa colonized with pulmonary pathogens, with an $\sim 10$-fold increased risk for pneumonia during the first $6 \mathrm{~d}$ of ICU stay. ${ }^{120}$

Oral chlorhexidine or topical antibiotic (selective decontamination) therapy has been reported to reduce the incidence of nosocomial pneumonia by an average of $40 \%$, with the highest reduction $(69 \%)$ reported in postoperative cardiac surgery subjects. ${ }^{121,122}$ However, a recent metaanalysis of oral chlorhexidine treatment suggests that it does not reduce the incidence of VAP in the general ICU population. ${ }^{123}$ Irrespective of these findings, the extent to which oral care with chlorhexidine would be effective in patients with advanced periodontal/dental disease is unknown.

Vulnerable populations are more likely to suffer from chronic malnutrition, which also is a significant risk factor 
for VAP. Admission serum albumin below $2.2 \mathrm{~g} / \mathrm{dL}$ is associated with a 6-fold higher incidence of VAP. ${ }^{124} \mathrm{Cu}$ mulative energy deficits among mechanically ventilated medical ICU subjects have been associated with increasing risk of VAP from 3- to 16-fold as energy deficits rise from 30 to $67 \% .^{125}$

\section{Traumatic Injuries}

Because of the complexity of caring for patients with traumatic injury, the VAP bundle is not always practical, and adherence fluctuates over time. ${ }^{9}$ VAP bundle adherence was less frequently achieved in those with more severe injuries (Injury Severity Scores of $>25$ ). ${ }^{9}$ Furthermore, VAP prevention measures are unlikely to be effective in some patients, particularly the subset of surgical/trauma patients with extensive abdominal pathology, as many have abdominal compartment syndrome. These patients have an inordinate number of risk factors for VAP: (1) they typically require frequent transportation outside the ICU; (2) they often can be placed only in a supine position; (3) they frequently require an oro- or nasogastric tube; (4) they have decreased bowel motility and subsequent colonization with pathogenic organisms; and (5) they are susceptible to gastric reflux, which is further enhanced by elevated intra-abdominal pressure. ${ }^{126,127}$ Even when patients requiring an oro- or nasogastric tube can be positioned optimally, gastroesophageal reflex cannot be prevented in mechanically ventilated patients. ${ }^{127}$ Therefore, the risk for microaspiration of contaminated gastric secretions cannot be fully prevented despite meticulous oral care. Moreover, even the radical therapy of selective digestive decontamination, whereby the entire aerodigestive tract is decontaminated by combined topical and parental prophylactic antibiotic therapy, generally reduces the risk of developing VAP by $\sim 50 \% .126$

Brain injury and other forms of trauma are recognized to cause immunosuppression and therefore increase the risk of VAP. ${ }^{128,129}$ When traumatic brain injury occurs in the context of other traumatic injuries, the prevalence and incidence of VAP are higher (30\% vs $23 \%, 28.2$ vs 22.5 cases/1,000 ventilator days). ${ }^{130}$ Immunosuppression in general increases the risk of VAP by a factor of 2.5.131 In addition, factors common in neurosurgical/trauma patients, such as blood transfusions, ${ }^{132}$ blunt chest trauma, ${ }^{40}$ aggressive fluid resuscitation, ${ }^{133}$ and loss of consciousness leading to aspiration, are all risk factors for VAP.

Furthermore, ARDS carries a substantial risk for developing VAP. ${ }^{134,135}$ Although some risk is related to the prolonged duration of mechanical ventilation, damage to the lung architecture from severe inflammation as well as macrophage dysfunction may increase the vulnerability of these patients to VAP. ${ }^{1}$ The incidence of VAP in patients with ARDS has ranged from 15 to $60 \%$ (average of 38\%), yet evidence suggests that lung-protective ventilation may be decreasing the incidence (29\%). ${ }^{136}$ Similar to other studies, the daily hazard for VAP in ARDS is most pronounced between days 6 and $10 .{ }^{136}$ Moreover, recent evidence suggests an inter-related genetic predisposition in some critically ill patients toward developing both VAP and ARDS. ${ }^{137}$

\section{Do Zero Ventilator-Associated Pneumonia Rates With Bundled Care Possess Evidence-Based Credibility?}

\author{
$100 \%$ compliance does not guarantee $100 \%$ preven- \\ tion-Croce et $\mathrm{al}^{9}$
}

That a zero VAP rate has been reported with adherence to the VAP bundle provides prima face justification for regulatory bodies and insurance companies to declare VAP a preventable and non-reimbursable event. Some of the most frequently cited studies supporting the achievement of zero VAP are based upon surveillance data from one private hospital in São Paulo, Brazil. ${ }^{138,139}$ However, even these studies were able to reach a zero VAP rate for only a few months when ventilator bundle adherence was $>95 \% .{ }^{139}$ In contrast, the first prospective multi-center study (in a predominantly medical ICU setting) linking bundled preventive care with VAP reduction demonstrated that $95 \%$ adherence produced a $59 \%$ decrease in VAP, whereas ICUs reporting at least a $20 \%$ improvement in VAP bundle adherence had a $45 \%$ decrease in VAP. ${ }^{140}$ In other words, a nearly 5 -fold increase in bundle adherence was required to yield a $14 \%$ absolute (31\% relative) improvement in VAP reduction.

Further misconceptions regarding the plausibility of a zero VAP rate may have been introduced by the Michigan Keystone collaborative report, wherein the reduction in median cases of VAP from 6 to 0 was emphasized. ${ }^{141}$ In contrast, the corresponding mean VAP incidence decreased by $49 \%$ from 6.9 to 3.4 cases $/ 1,000$ ventilator days. Interestingly, the $\sim 75 \%$ bundle adherence achieved happened in the context of ICUs being encouraged to conduct quality-improvement evaluations at one reference time point, twice per week during morning rounds. This introduced the likelihood of bias toward higher bundle adherence than would be expected with unplanned, random assessments over a 24 -h period.

In contrast, a European study of VAP bundle care chose to record the lowest daily adherence and found a $25 \%$ relative reduction in VAP (15.5 to $11.7 \%, 12.9$ to 9.3 cases/1,000 ventilator days) despite an overall nadir adherence of $<30 \%$. ${ }^{142}$ These investigators found that not all bundle measures had equal impact on VAP reduction. For example, adherence to hand hygiene reduced the risk 
of developing VAP by 65\%, compared with monitoring ETT cuff pressure (79\%) and oral hygiene (77\%). Moreover, this study challenged the conventional all-or-nothing assumption on the effectiveness of the VAP bundle.

The legitimacy of inter-facility comparisons of VAP rates necessarily assumes that case mixes with varying risk factors can be controlled for during analysis. In reality, this requires laborious patient-based data collection and is of questionable feasibility. Stated differently, can VAP rates reasonably be reduced in hospitals serving high-risk patient populations if these institutions could perform preventive measures at a very high rate? A recent European study using surveillance data from over 78,000 subjects in 525 ICUs attempted to answer this question. ${ }^{143}$ The projected VAP rates were based upon the top-tenth percentileranked ICUs reflecting the lowest infection rates. When adjustments were made for case mixes, hospitals with the highest infection rates were projected to prevent $\sim 52 \%$ of their VAP cases, which is similar to other published estimates, ${ }^{144}$ as well as recently published data from the California Partnership for Health. ${ }^{145}$

\section{Summary}

The most common of all follies is to believe passionately in the palpably not true. It is the chief occupation of mankind.-HL Mencken

Taken together, the evidence presented in this review suggests that significant reductions in VAP are possible and that the goal of reducing VAP by $50 \%$ or greater is realistic. However, exaggerated claims of eradicating VAP are harmful both to clinical science and public policy discourse alike. For example, the Institute for Healthcare Improvement 5 Million Lives Campaign stated that 25 participating facilities self-reported having "gone over a year without a ventilator-associated pneumonia...demonstrating that this sort of complication is avoidable and is not inevitable." 17 However, these facilities represented $<1 \%$ of the Institute for Healthcare Improvement's participating institutions and whose patient population was not described. The popular promotion of zero VAP deviates from the principles of evidenced-based practice. Some have opined that because human lives are at stake, there is an understandable tendency for critical interpretation of data to be "eclipsed by the immediate need to do something." 49 This is a generous but ultimately facile explanation, particularly given the pervasive and enthusiastic embracing of zero VAP within a wide swath of the health-care community.

There are striking similarities between the fervent belief that VAP can be eradicated and the phenomenon social scientists refer to as mass conversion disorder. ${ }^{146,147}$ More commonly known as collective delusion, it has a storied history in human culture. ${ }^{148,149}$ In essence, when a social group perceives an external threat, it may in turn misperceive common phenomena as suddenly threatening, resulting in false attributions and irrational decisions. Irrationality is defined as "coming to conclusions that cannot be justified by current knowledge." 150 Social delusions can be exacerbated by the reinforcing behaviors of external entities, such as companies marketing products to prevent VAP, as well as self-promoting public advocacy groups. In this regard, it cannot escape notice that the Institute for Healthcare Improvement's 5 Million Lives Campaign functioned as a fundraising tool. ${ }^{17}$

Health care in the United States has been under economic pressure for decades, which has only intensified with the looming prospect of an aging baby-boomer generation. The current efforts to reduce patient harm and costs are refreshing, laudable, and necessary. Unfortunately, this becomes problematic when the desire to improve patient care either distorts or ignores the principles of evidence-based practice and unwittingly threatens the reputation and economic viability of hospitals. It is a welcomed sign that, in the face of mounting opposition, regulatory agencies have temporarily backed away from imposing draconian measures regarding VAP. However, members of the health-care professions themselves unintentionally contributed to this problem through a lack of appropriate skepticism. This should give pause for collective self-reflection.

\section{REFERENCES}

1. Chastre J, Fagon JY. Ventilator-associated pneumonia. Am J Respir Crit Care Med 2002;165(7):867-903.

2. Ewig S, Torres A, El-Ebiary M, Fábregas N, Hernández C, González $\mathrm{J}$, et al. Bacterial colonization patterns in mechanically ventilated patients with traumatic and medical head injury. Am J Respir Crit Care Med 1999;159(1):188-198.

3. Sackner MA, Hirsch J, Epstein S. Effect of cuffed endotracheal tubes on tracheal mucous velocity. Chest 1975;68(6):774-777.

4. Konrad F, Schreiber T, Brecht-Kraus D, Georgieff M. Mucociliary transport in ICU patients. Chest 1994;105(1):237-241.

5. Safdar N, Crnich CJ, Maki DG. The pathogenesis of ventilatorassociated pneumonia: its relevance to developing effective strategies for prevention. Respir Care 2005;50(6):725-739; discussion 739741.

6. Craven DE, Hudcova J, Craven KA, Scopa C, Lei Y. Antibiotic treatment of ventilator-associated tracheobronchitis: to treat or not to treat? Curr Opin Crit Care 2014;20(5):532-541.

7. Melsen WG, Rovers MM, Koeman M, Bonten MJ. Estimating the attributable mortality of ventilator-associated pneumonia from randomized prevention studies. Crit Care Med 2011;39(12):2736-2742.

8. Safdar N, Dezfulian C, Collard HR, Saint S. Clinical and economic consequences of ventilator-associated pneumonia: a systematic review. Crit Care Med 2005;33(10):2184-2193.

9. Croce MA, Brasel KJ, Coimbra R, Adams CA Jr, Miller PR, Pasquale $\mathrm{MD}$, et al. National Trauma Institute prospective evaluation of the ventilator bundle in trauma patients: does it really work? J Trauma Acute Care Surg 2013;74(2):354-360; discussion 360-362. 
10. Grgurich PE, Hudcova J, Lei Y, Sarwar A, Craven DE. Diagnosis of ventilator-associated pneumonia: controversies and working toward a gold standard. Curr Opin Infect Dis 2013;26(2):140-150.

11. Shorr AF, Chan CM, Zilberberg MD. Diagnostics and epidemiology in ventilator-associated pneumonia. Ther Adv Respir Dis 2011;5(2): 121-130.

12. Warren DK, Shukla SJ, Olsen MA, Kollef MH, Hollenbeak CS, Cox MJ, et al. Outcome and attributable cost of ventilator-associated pneumonia among intensive care unit patients in a suburban medical center. Crit Care Med 2003;31(5):1312-1317.

13. Zimlichman E, Henderson D, Tamir O, Franz C, Song P, Yamin CK, et al. Health care-associated infections: a meta-analysis of costs and financial impact on the US health care system. JAMA Intern Med 2013;173(22):2039-2046.

14. Rello J, Ollendorf DA, Oster G, Vera-Llonch M, Bellm L, Redman $\mathrm{R}$, et al. Epidemiology and outcomes of ventilator-associated pneumonia in a large US database. Chest 2002;122(6):2115-2121.

15. Kmietowicz Z. Health staff know where savings can be made, says US “zero harm” expert. BMJ 2013;346:f2506.

16. Murray AS, Griswold M, Sunesara I, Smith E. Comparison of patient outcomes in academic medical centers with and without value analysis programs. J Healthc Leadersh 2012;4:93-105.

17. Institute for Health Care Improvement. Five million lives campaign. An initiative of the Institute for Health Care Improvement 2006. http://www.ihi.org/Engage/Initiatives/Completed/5Million LivesCampaign/Pages/default.aspx. Accessed May 20, 2015.

18. Magill SS, Klompas M, Balk R, Burns SM, Deutschman CS, Diekma $\mathrm{D}$, et al. Developing a new national approach to surveillance for ventilator-associated events: executive summary. Infect Control Hosp Epidemiol 2013;34(12):1239-1243.

19. Klompas M, Kalil AC. The "last breath" of the ventilator-associated pneumonia surveillance definition. Crit Care Med 2014;42(3):722723.

20. Niederman MS. The clinical diagnosis of ventilator-associated pneumonia. Respir Care 2005;50(6):788-796; discussion 807-812.

21. Nussenblatt V, Avdic E, Berenholtz S, Daugherty E, Hadhazy E, Lipsett PA, et al. Ventilator-associated pneumonia: overdiagnosis and treatment are common in medical and surgical intensive care units. Infect Control Hosp Epidemiol 2014;35(3):278-284.

22. Klompas M, Kulldorff M, Platt R. Risk of misleading ventilatorassociated pneumonia rates with use of standard clinical and microbiologic criteria. Clin Infect Dis 2008;46(9):1443-1446.

23. Papazian L, Autillo-Touati A, Thomas P, Bregeon F, Garbe L, Saux $\mathrm{P}$, et al. Diagnosis of ventilator-associated pneumonia: an evaluation of direct examination and presence of intracellular organisms. Anesthesiology 1997;87(2):268-276.

24. Fàbregas N, Ewig S, Torres A, El-Ebiary M, Ramirez J, de la Bellacasa JP, et al. Clinical diagnosis of ventilator-associated pneumonia revisited: comparative validation using immediate post-mortem lung biopsies. Thorax 1999;54(10):867-873.

25. American Thoracic Society, Infectious Diseases Society of America. Guidelines for the management of adults with hospital-acquired, ventilator-associated, and healthcare-associated pneumonia. Am J Respir Crit Care Med 2005;171(4):388-416.

26. Skrupky LP, McConnell K, Dallas J, Kollef MH. A comparison of ventilator-associated pneumonia rates as identified according to the National Healthcare Safety Network and American College of Chest Physicians criteria. Crit Care Med 2012;40(1):281-284.

27. Klompas M. Is a ventilator-associated pneumonia rate of zero really possible? Curr Opin Infect Dis 2012;25(2):176-182.

28. Stevens JP, Kachniarz B, Wright SB, Gillis J, Talmor D, Clardy P, Howell MD. When policy gets it right: variability in US hospitals' diagnosis of ventilator-associated pneumonia. Crit Care Med 2014; 42(3):497-503.
29. Kollef MH. Ventilator-associated tracheobronchitis and ventilatorassociated pneumonia. Chest 2013;144(1):3-5.

30. Klompas M. Interobserver variability in ventilator-associated pneumonia surveillance. Am J Infect Control 2010;38(3):237-239.

31. Iregui M, Ward S, Sherman G, Fraser VJ, Kollef MH. Clinical importance of delays in the initiation of appropriate antibiotic treatment for ventilator-associated pneumonia. Chest 2002;122(1):262268.

32. Mietto C, Pinciroli R, Patel N, Berra L. Ventilator-associated pneumonia: evolving definitions and preventive strategies. Respir Care 2013;58(6):990-1007.

33. Uçkay I, Ahmed QA, Sax H, Pittet D. Ventilator-associated pneumonia as a quality indicator for patient safety? Clin Infect Dis 2008; 46(4):557-563.

34. Magill SS, Fridkin SK. Improving surveillance definitions for ventilator-associated pneumonia in an era of public reporting and performance measurement. Clin Infect Dis 2012;54(3):378-380.

35. Klompas M. Complications of mechanical ventilation-the CDC's new surveillance paradigm. N Engl J Med 2013;368(16):1472-1475.

36. Thomas BW, Maxwell RA, Dart BW, Hartmann EH, Bates DL, Mejia VA, et al. Errors in administrative-reported ventilator-associated pneumonia rates: are never events really so? Am Surg 2011; 77(8):998-1002.

37. Sundar KM, Nielsen D, Sperry P. Comparison of ventilator-associated pneumonia (VAP) rates between different ICUs: implications of a zero VAP rate. J Crit Care 2012;27(1):26-32.

38. Klompas M. Ventilator-associated pneumonia - the wrong quality measure for benchmarking. Ann Intern Med 2007;147(11):803-805.

39. Blot S, Lisboa T, Angles R, Rello J. Prevention of VAP: is zero rate possible? Clin Chest Med 2011;32(3):591-599.

40. Michetti CP, Fakhry SM, Ferguson PL, Cook A, Moore FO, Gross R, AAST Ventilator-Associated Pneumonia Investigators. Ventilator-associated pneumonia rates at major trauma centers compared with a national benchmark: a multi-institutional study of the AAST. J Trauma Acute Care Surg 2012;72(5):1165-1173.

41. Walsh TS, Morris AC, Simpson AJ. Ventilator-associated pneumonia: can we ensure that a quality indicator does not become a game of chance? Brit J Anaesth 2013;111(3):333-337.

42. Dalmora CH, Deutschendorf C, Nagel F, dos Santos RP, Lisboa T. Defining ventilator-associated pneumonia: a (de)construction concept. Rev Bras Ter Intensive 2013;25(2):81-86

43. Halpern NA, Hale KE, Sepkowitz KA, Pastores SM. A world without ventilator-associated pneumonia: time to abandon surveillance and deconstruct the bundle. Crit Care Med 2012;40(1):267-270.

44. Klompas M. What can we learn from international ventilator-associated pneumonia rates? Crit Care Med 2012;40(12):3303-3304.

45. Rosenthal VD, Rodrigues C, Álvarez-Moreno C, Madani N, Mitrev Z, Ye G, et al. Effectiveness of a multidimensional approach for prevention of ventilator-associated pneumonia in adult intensive care units from 14 developing countries of 4 continents: findings of the International Nosocomial Infection Control Consortium. Crit Care Med 2012;40(12):3121-3128.

46. Ding S, Kilickaya O, Senkal S, Gajic O, Hubmayr RD, Li G. Temporal trends of ventilator-associated pneumonia incidence and the effect of implementing health-care bundles in a suburban community. Chest 2013;144(5):1461-1468.

47. Lisboa T, Rello J. Towards zero rate in healthcare-associated infections: one size shall not fit all. Crit Care 2013;17(3):139.

48. Wunderink RG. Ventilator-associated complications, ventilator-associated pneumonia, and Newton's third law of mechanics. Am J Respir Crit Care Med 2014;189(8):882-883.

49. Zilberberg MD, Shorr AF. Quality indicators: not everything that can be counted counts. Crit Care Med 2014;42(8):1946-1947. 
50. Klompas M. Ventilator-associated pneumonia: is zero possible? Clin Infect Dis 2010;51(10):1123-1126.

51. Levy MM. A new definition of ventilator-associated pneumonia: far from perfect, better than before. Ann Am Thorac Soc 2013;10(6): 644-645.

52. Klein Klouwenberg PM, van Mourik MS, Ong DS, Horn J, Schultz MJ, Cremer OL, et al. Electronic implementation of a novel surveillance paradigm for ventilator-associated events. Am J Respir Crit Care Med 2014;189(8):947-955.

53. Muscedere J, Sinuff T, Heyland DK, Dodek PM, Keenan SP, Wood G. The clinical impact and preventability of ventilator-associated conditions in critically-ill patients who are mechanically ventilated. Chest 2013;144(5):1453-1460.

54. Klompas M, Kleinman K, Murphy MV. CDC Prevention Epicenters Program. Descriptive epidemiology and attributive morbidity of ventilator-associated events. Infect Control Hosp Epidemiol 2014;35(5): 502-510.

55. Chang HC, Chen CM, Kung SC, Wang CM, Liu WL, Lai CC. Differences between novel and conventional surveillance paradigms of ventilator associated pneumonia. Am J Infect Control 2015;43(2): 133-136.

56. Stoeppel CM, Eriksson EA, Hawkins K, Eastman A, Wolf S, Minei J, Minshall CT. Applicability of the National Healthcare Safety Network's surveillance definition of ventilator-associated events in the surgical intensive care unit: a 1-year review. J Trauma Acute Care Surg 2014;77(6):934-937.

57. Lewis SC, Li L, Murphy MV, Klompas M, CDC Prevention Epicenters. Risk factors for ventilator-associated events: a case-control multivariable analysis. Crit Care Med 2014;42(8):1839-1848.

58. Lilly CM, Ellison RT. Quality measures for critically ill patients. Where does ventilator-associated condition fit in? Chest 2013;144(5): 1429-1430.

59. Cohn SM, DuBose JJ. Pulmonary contusion: an update on recent advances in clinical management. World J Surg 2010;34(8):19591970.

60. Kollef MH. What is ventilator-associated pneumonia and why is it important? Respir Care 2005;50(6):714-721; discussion 721-724.

61. Vallés J, Pobo A, García-Esquirol O, Mariscal D, Real J, Fernández R. Excess ICU mortality attributable to ventilator-associated pneumonia: the role of early vs late onset. Intensive Care Med 2007; 33(8):1363-1368.

62. Giard M, Lepape A, Allaouchiche B, Guerin C, Lehot JJ, Robert $\mathrm{MO}$, et al. Early- and late-onset ventilator-associated pneumonia acquired in the intensive care unit: comparison of risk factors. J Crit Care 2008;23(1):27-33.

63. Jaimes F, De La Rosa G, Gómez E, Múnera P, Ramírez J, Castrillón $\mathrm{S}$. Incidence and risk factors for ventilator-associated pneumonia in a developing country: where is the difference? Respir Med 2007; 101(4):762-767.

64. Linton RC, Walker FW, Spoerel WE. Respirator care in a general hospital: a five-year survey. Can Anaesth Soc J 1965;12(5):451-457.

65. Hess D. Infection control in the intensive care unit. The role of the ventilator circuit. Minerva Anestesiol 2002;68(5):356-359.

66. Branson RD. The ventilator circuit and ventilator-associated pneumonia. Respir Care 2005;50(6):774-785; discussion 785-787.

67. Jaillette E, Martin-Loeches I, Artigas A, Nseir S. Optimal care and design of the tracheal cuff in the critically ill patient. Ann Intensive Care 2014;4(1):7.

68. Seegobin RD, van Hasselt GL. Aspiration beyond endotracheal cuffs. Can Anaesth Soc J 1986;33(3 Pt 1):273-279.

69. Mahul P, Auboyer C, Jospe R, Ros A, Guerin C, el Khouri Z, et al. Prevention of nosocomial pneumonia in intubated patients: respective role of mechanical subglottic secretions drainage and stress ulcer prophylaxis. Intensive Care Med 1992;18(1):20-25.
70. Dullenkopf A, Gerber A, Weiss M. Fluid leakage past tracheal tube cuffs: evaluation of the new Microcuff endotracheal tube. Intensive Care Med 2003;29(10):1849-1853.

71. Kolobow T, Cressoni M, Epp M, Corti I, Cadringher P, Zanella A. Comparison of a novel Lycra endotracheal tube cuff to standard polyvinyl chloride cuff and polyurethane cuff for fluid leak prevention. Respir Care 2011;56(8):1095-1099.

72. Lorente L, Lecuona M, Jiménez A, Mora ML, Sierra A. Influence of an endotracheal tube with polyurethane cuff and subglottic secretion drainage on pneumonia. Am J Respir Crit Care Med 2007;176(11): 1079-1083.

73. Mehta S, Myat HM. The cross-sectional shape and circumference of the human trachea. Ann R Coll Surg Engl 1984;66(5):356-358.

74. Young PJ, Rollinson M, Downward G, Henderson S. Leakage of fluid past the tracheal tube cuff in a benchtop model. Brit J Anaesth 1997;78(5):557-562.

75. Young PJ, Pakeerathan S, Blunt MC, Subramanya S. A low-volume, low-pressure tracheal tube cuff reduces pulmonary aspiration. Crit Care Med 2006;34(3):632-639.

76. McGovern Murphy F, Raymond M, Menard PA, Bejar-Ardiles KR, Carignan A, Lesur O. Ventilator-associated pneumonia and endotracheal tube repositioning: an underrated risk factor. Am J Infect Control 2014;42(12):1328-1330.

77. Dave MH, Frotzler A, Madjdpour C, Koepfer N, Weiss M. Massive aspiration past the tracheal tube cuff caused by closed tracheal suction system. J Intensive Care Med 2011;26(5):326-329.

78. Lucangelo U, Zin WA, Antonaglia V, Petrucci L, Viviani M, Buscema $\mathrm{G}$, et al. Effect of positive expiratory pressure and type of tracheal cuff on the incidence of aspiration in mechanically ventilated patients in an intensive care unit. Crit Care Med 2008;36(2):409-413.

79. Sottile FD, Marrie TJ, Prough DS, Hobgood CD, Gower DJ, Webb LX, et al. Nosocomial pulmonary infection: possible etiologic significance of bacterial adhesion to endotracheal tubes. Crit Care Med 1986;14(4):265-270.

80. Pinciroli R, Mietto C, Berra L. Respiratory therapy device modifications to prevent ventilator-associated pneumonia. Curr Opin Infect Dis 2013;26(2):175-183.

81. De Souza PR, De Andrade D, Cabral DB, Watanabe E. Endotracheal tube biofilm and ventilator-associated pneumonia with mechanical ventilation. Microsc Res Tech 2014;77(4):305-312.

82. Wilson A, Gray D, Karakiozis J, Thomas J. Advanced endotracheal tube biofilm stage, not duration of intubation, is related to pneumonia. J Trauma Acute Care Surg 2012;72(4):916-923.

83. Berra L, Coppadoro A, Bittner EA, Kolobow T, Laquerriere P, Pohlmann JR, et al. A clinical assessment of Mucus Shaver: a device to keep the endotracheal tube free of bacteria. Crit Care Med 2012; 40(1):119-124.

84. Muscedere J, Rewa O, McKechnie K, Jiang X, Laporta D, Heyland DK. Subglottic secretion drainage for prevention of ventilator-associated pneumonia: a systematic review and meta-analysis. Crit Care Med 2011;39(8):1985-1991.

85. Li Bassi G, Ranzani OT, Marti JD, Giunta V, Luque N, Isetta V, et al. An in vitro study to assess determinant features associated with fluid sealing in the design of endotracheal tube cuffs and exerted tracheal pressures. Crit Care Med 2013;41(2):518-526.

86. Lau AC, Lam SM, Yan WW. Benchtop study of leakage across the Portex, TaperGuard, and Microcuff endotracheal tubes under simulated clinical conditions. Hong Kong Med J 2014;20(1):7-15.

87. Zanella A, Scaravilli V, Isgrò S, Milan M, Cressoni M, Patroniti N, et al. Fluid leakage across tracheal tube cuff, effect of different cuff material, shape, and positive expiratory pressure: a bench-top study. Intensive Care Med 2011;37(2):343-347.

88. Miller MA, Arndt JL, Konkle MA, Chenoweth CE, Iwashyna TJ, Flaherty KR, Hyzy RC. A polyurethane cuffed endotracheal tube is 
associated with decreased rates of ventilator-associated pneumonia. J Crit Care 2011;26(3):280-286.

89. Poelaert J, Depuydt P, De Wolf A, Van de Velde S, Herck I, Blot S. Polyurethane cuffed endotracheal tubes to prevent early postoperative pneumonia after cardiac surgery: a pilot study. J Thorac Cardiovasc Surg 2008;135(4):771-776.

90. Mahmoodpoor A, Peyrovi-far A, Hamishehkar H, Bakhtyiari Z, Mirinezhad MM, Hamidi M, Golzari SE. Comparison of prophylactic effects of polyurethane cylindrical or tapered cuff and polyvinyl chloride cuff endotracheal tubes on ventilator-associated pneumonia. Acta Medica Iranica 2013;51(7):461-466.

91. Bulpa P, Evrard P, Bouhon S, Schryvers F, Jamart J, Michaux I, et al. Polyurethane does not protect better than polyvinyl cuffed tracheal tubes from microaspirations. Minerva Anestesiol 2013;79(5): 498-503.

92. Kollef MH, Von Harz B, Prentice D, Shapiro SD, Silver P, St John $\mathrm{R}$, Trovillion E. Patient transport from intensive care increases the risk of developing ventilator-associated pneumonia. Chest 1997; 112(3):765-773.

93. Bercault N, Wolf M, Runge I, Fleury JC, Boulain T. Intrahospital transport of critically ill ventilated patients: a risk factor for ventilator-associated pneumonia - a matched cohort study. Crit Care Med 2005;33(11):2471-2478.

94. Rouzé A, Jaillette E, Nseir S. Continuous control of tracheal cuff pressure: an effective measure to prevent ventilator associated pneumonia? Crit Care 2014;18(5):512.

95. Nseir S, Zerimech F, Fournier C, Lubret R, Ramon P, Durocher A, Balduyck M. Continuous control of tracheal cuff pressure and microaspiration of gastric contents in critically-ill patients. Am J Respir Crit Care Med 2011;184(9):1041-1047.

96. Lorente L, Lecuona M, Jiménez A, Lorenzo L, Roca I, Cabera J, et al. Continuous endotracheal tube cuff pressure control system protects against ventilator-associated pneumonia. Crit Care 2014;18(2): R77.

97. Hess DR. Noninvasive positive-pressure ventilation and ventilatorassociated pneumonia. Respir Care 2005;50(7):924-929; discussion 929-931.

98. Kohlenberg A, Schwab F, Behnke M, Geffers C, Gastmeier P. Pneumonia associated with invasive and noninvasive ventilation: an analysis of the German nosocomial infection surveillance system database. Intensive Care Med 2010;36(6):971-978.

99. Esteban A, Frutos F, Tobin MJ, Alía I, Solsona JF, Valverdú I, et al. The Spanish Lung Failure Collaborative Group. A comparison of four methods of weaning patients from mechanical ventilation. N Engl J Med 1995;332(6):345-350.

100. Esteban A, Alía I, Ibañez J, Benito S, Tobin MJ. Modes of mechanical ventilation and weaning. A national survey of Spanish hospitals. The Spanish Lung Failure Collaborative Group. Chest 1994;106(4):1188-1193

101. Ely EW, Baker AM, Dunagan DP, Burke HL, Smith AC, Kelly PT, et al. Effect on the duration of mechanical ventilation of identifying patients capable of breathing spontaneously. N Engl J Med 1996; 335(25): 1864-1869.

102. Tonnelier A, Tonnelier JM, Nowak E, Gut-Gobert C, Prat G, Renault $\mathrm{A}$, et al. Clinical relevance of classification according to weaning difficulty. Respir Care 2011;56(5):583-590.

103. Kress JP, Pohlman AS, O'Connor MF, Hall JB. Daily interruption of sedative infusions in critically ill patients undergoing mechanical ventilation. N Engl J Med 2000;342(20):1471-1477.

104. Girard TD, Kress JP, Fuchs BD, Thomason JW, Schweickert WD, Pun BT, et al. Efficacy and safety of a paired sedation and ventilator weaning protocol for mechanically ventilated patients in intensive care (Awake and Breathing Controlled trial): a randomized controlled trial. Lancet 2008;371(9607):126-134.
105. Quenot JP, Ladoire S, Devoucoux F, Doise JM, Cailliod R, Cunin, et al. Effect of a nurse-implemented sedation protocol on the incidence of ventilator-associated pneumonia. Crit Care Med 2007; 35(9):2031-2036.

106. Dries DJ, McGonigal MD, Malian MS, Bor BJ, Sullivan C. Protocol-driven ventilator-weaning reduces use of mechanical ventilation, rate of early reintubation, and ventilator-associated pneumonia. J Trauma 2004;56(5):943-951; discussion 951-952.

107. De Jonghe B, Bastuji-Garin S, Fangio P, Lacherade JC, Jabot J, Appéré-De-Vecchi C, et a;. Sedation algorithm in critically ill patients without acute brain injury. Crit Care Med 2005;33(1):120127.

108. Torres A, Serra-Batlles J, Ros E, Piera C, de la Bellacasa JP, Cobos A, et al. Pulmonary aspiration of gastric contents in patients receiving mechanical ventilation: the effect of body position. Ann Intern Med 1992;116(7):540-543.

109. Ibáñez J, Peñafiel A, Raurich JM, Marse P, Jordá R, Mata F. Gastroesophageal reflux in intubated patients receiving enteral nutrition: effect of supine and semirecumbent positions. JPEN J Parenter Enteral Nutr 1992;16(5):419-422.

110. Drakulovic MB, Torres A, Bauer TT, Nichols JM, Nogué S, Ferrer M. Supine body position as a risk factor for nosocomial pneumonia in mechanically ventilated patients: a randomized trial. Lancet 1999; 345(9193):1851-1858.

111. Ferrer M, Bauer TT, Torres A, Hernández C, Piera C. Effect of nasogastric tube size on gastroesophageal reflux and microaspiration in intubated patients. Ann Intern Med 1999;130(12):991-994.

112. van Nieuwenhoven CA, Vandenbroucke-Grauls C, van Tiel FH, Joore HC, Strack van Schijndel RJ, van der Tweel I, et al. Feasibility and effects of the semirecumbent position to prevent ventilator-associated pneumonia: a randomized study. Crit Care Med 2006;34(2):396-402.

113. Niël-Weise BS, Gastmeier P, Kola A, Vonberg RP, Wille JC, van den Broek, Bed Head Elevation Study Group. An evidence-based recommendation on bed head elevation for mechanically ventilated patients. Crit Care 2011;15(2):R111.

114. Alexiou VG, Ierodiakonou V, Dimopoulos G, Falagas ME. Impact of patient position on the incidence of ventilator-associated pneumonia: a meta-analysis of randomized controlled trials. J Crit Care 2009;24(4):515-522.

115. Silvestri L, Gregori D, van Saene HK, Belli R, Blazic M. Semirecombent position to prevent ventilator-associated pneumonia is not evidence based. J Crit Care 2010;25(1):152-153.

116. Alexiou VG, Dimopoulos G, Falagas ME. Re: Semirecombent position to prevent ventilator-associated pneumonia is not evidence based. J Crit Care 2010;25(1):153-154.

117. Caplan DJ, Weintraub JA. The oral health burden in the United States: a summary of recent epidemiologic studies. J Dent Educ 1993;57(12):853-862.

118. Seirawan H, Elizondo LK, Nathason N, Mulligan R. The oral health conditions of the homeless in downtown Los Angeles. J Calif Dent Assoc 2010;38(9):681-688.

119. Borrell LN, Crawford ND. Socioeconomic position indicators and periodontitis: examining the evidence. Periodontol 2000 2012;58(1): 69-83.

120. Scannapieco FA, Bush RB, Paju S. Associations between periodontal disease and risk for nosocomial bacterial pneumonia and chronic obstructive pulmonary disease. A systematic review. Ann Periodontol 2003;8(1):54-69.

121. Shi Z, Xie H, Wang P, Zhang Q, Wu Y, Chen E, et al. Oral hygiene care for critically ill patients to prevent ventilator-associated pneumonia. Cochrane Database Syst Rev 2013;8:CD008367. 
122. Richards D. Oral hygiene regimes for mechanically ventilated patients that use chlorhexidine reduce ventilator-associated pneumonia. Evid Based Dent 2013;14(3):91-92.

123. Klompas M, Speck K, Howell MD, Greene LR, Berenholtz SM. Reappraisal of routine oral care with chlorhexidine gluconate for patients receiving mechanical ventilation: systematic review and meta-analysis. JAMA Intern Med 2014;174(5):751-761.

124. George DL, Falk PS, Wunderink RG, Leeper KV Jr, Meduri GU, Steere EL, et al. Epidemiology of ventilator-acquired pneumonia based on protected bronchoscopic sampling. Am J Respir Crit Care Med 1998;158(6):1839-1847.

125. Faisy C, Candela Llerena M, Savalle M, Mainardi JL, Fagon JY. Early ICU energy deficit is a risk factor for Staphylococcus aureus ventilator-associated pneumonia. Chest 2011;140(5):1254-1260.

126. Kallet RH, Quinn TE. The gastrointestinal tract and ventilatorassociated pneumonia. Respir Care 2005;50(7):910-921; discussion 921-923.

127. Orozco-Levi M, Torres A, Ferrer M, Piera C, El-Ebiary M, de la Bellacasa JP, Rodriguez-Roisin R. Semirecumbent position protects from pulmonary aspiration but not completely from gastroesophageal reflux in mechanically ventilated patients. Am J Respir Crit Care Med 1995;152(4):1387-1390.

128. Fàbregas N, Torres A. Pulmonary infection in the brain injured patient. Minerva Anestesiol 2002;68(4):285-290.

129. Minei JP, Nathens AB, West M, Harbrecht BG, Moore EE, Shapiro $\mathrm{MB}$, et al. Inflammation and the host response to injury, a large scale collaborative project: patient-oriented research core-standard operating procedures for clinical care. II. Guidelines for prevention, diagnosis and treatment of ventilator-associated pneumonia (VAP) in trauma patients. J Trauma 2006;60(5):1106-1113; discussion 1113.

130. Dricken J, Murphy T, Hashmi O, Frotan M, Simmons J, Brevard S. Ventilator-associated pneumonia rates in a trauma ICU: the impact of traumatic brain injury (abstract). Crit Care Med 2013;41(12): 1089.

131. Kollef MH, Ward S. The influence of mini-BAL cultures on patient outcomes. Implications for the antibiotic management of ventilatorassociated pneumonia. Chest 1998;113(2):412-420.

132. Bochicchio GV, Napolitano L, Joshi M, Bochicchio K, Shih D, Meyer W, Scalea TM. Blood product transfusion and ventilatorassociated pneumonia in trauma patients. Surg Infect 2008;9(4): 415-422.

133. Mekontso Dessap A, Katsahian S, Roche-Campo F, Varet H, Kouatchet A, Tomicic V, et al. Ventilator-associated pneumonia during weaning from mechanical ventilation: role of fluid management. Chest 2014;146(1):58-65.

134. Chastre J, Trouillet JL, Vuagnat A, Joly-Guillou ML, Clavier H, Dombret MC, Gibert C. Nosocomial pneumonia in patients with acute respiratory distress syndrome. Am J Respir Crit Care Med 1998;157(4):1165-1172.
135. Markowicz P, Wolff M, Djedaïni K, Cohen Y, Chastre J, Delclaux $\mathrm{C}$, et al. Multicenter prospective study of ventilator-associated pneumonia during acute respiratory distress syndrome. Am J Respir Crit Care Med 2000;161(6):1942-1948.

136. Forel JM, Voillet F, Pulina D, Gacouin A, Perrin G, Barrau K, et al. Ventilator-associated pneumonia and ICU mortality in severe ARDS patients ventilated according to a lung-protective strategy. Crit Care 2012;16(2):R65.

137. Salnikova LE, Smelaya TV, Vesnina IN, Golubev AM, Moroz VV. Genetic susceptibility to nosocomial pneumonia, acute respiratory distress syndrome and poor outcome in patients at risk of critical illness. Inflammation 2014;37(2):295-305.

138. Marra AR, Cal RG, Silva CV, Caserta RA, Paes AT, Moura DF Jr, et al. Successful prevention of ventilator-associated pneumonia in an intensive care setting. Am J Infect Control 2009;37(8):619-625.

139. Caserta RA, Marra AR, Durão MS, Silva CV, dos Santos OF, et al. A program for sustained improvement in preventing ventilatorassociated pneumonia in an intensive care setting. BMC Infect Dis 2012;12:234.

140. Resar R, Pronovost P, Haraden C, Simmonds T, Rainey T, Nolan T. Using a bundle approach to improve ventilator care processes and reduce ventilator-associated pneumonia. Jt Comm J Qual Patient Saf 2005;31(5):243-248.

141. Berenholtz SM, Pham JC, Thompson DA, Needham DM, Lubomski LH, Hyzy RC, et al. Collaborative cohort study of an intervention to reduce ventilator-associated pneumonia in the intensive care unit. Infect Control Hosp Epidemiol 2011;32(4):305-314.

142. Rello J, Afonso E, Lisboa T, Ricart M, Balsera B, Rovira A, et al. A care bundle approach for prevention of ventilator-associated pneumonia. Clin Microbiol Infect 2013;19(4):363-369.

143. Lambert ML, Silversmit G, Savey A, Palomar M, Hiesmayr M, Agodi A, et al. Preventable proportion of severe infections acquired in intensive care units: case mix adjusted estimations from patientbased surveillance data. Infect Control Hosp Epidemiol 2014;35(5): 494-501.

144. Umscheid CA, Mitchell MD, Doshi JA, Agarwal R, Williams K, Brennan PJ. Estimating the proportion of healthcare-associated infections that are reasonably preventable and the related mortality and costs. Infect Control Hosp Epidemiol 2011;32(2):101-114.

145. Wang TI, Arias MM, Williams JA, Kun HM, Muñoz AA, Slininger J, et al. Patient safety first...a California Partnership for Health. Jt Comm J Qual Patient Saf 2014;40(5):205-211.

146. Bartholomew RE, Wessely S. Protean nature of mass sociogenic illness. Br J Psych 2002;180(4):300-306.

147. Weir E. Mass sociogenic illness. CMAJ 2005;172(1):36.

148. Storr A. Feet of clay: saints, sinners, and madness: a study of gurus. New York, NY: Simon \& Schuster; 1997:199.

149. Reznek L. Delusions and the madness of the masses. New York, New York: Rowman \& Littlefield Publishers; 2010.

150. Sutherland S. Irrationality: the enemy within. New York, New York: Penguin Books; 1994:10. 